\title{
Enhancing Oral Communication Skills in Mathematics Teaching: Lessons from Research
}

\author{
Dorcas Zuvalinyenga \\ Department of Languages and Communication Skills \\ Bindura University of Science Education \\ dzuvalinyenga@buse.ac.zw
}

\section{ABSTRACT}

This paper explores research on the enhancement of oral communication skills in mathematics teachers. The author reviewed four articles on the improvement of teaching and learning of mathematics. Research in this area is expanding rapidly. However, to date, few studies have critically investigated this body of work. The author reviewed key findings from influential studies. The author's analysis revealed that although these studies are subject to limitations, mathematics teachers' oral communication skills can be enhanced to improve the teaching and learning of the subject. Contemporary literature on the issue hypothesizes that the enhancement of oral communication skills promotes effective teaching and learning of the subject. The article concludes by identifying potential areas for further research.

\section{Keywords:}

oral communication, classroom communication, communication skills, instructional innovation, learning activities, teacher improvement.

\section{Introduction}

Due to the rapid advancement of science and technology as well as the importance of mathematics in education and industry, teachers need to be better educated in the teaching of the subject than their previous counterparts sought to be. They must be able to interpret and use mathematics to make sense of information and complex situations. They also need to develop and hone their skills through deeper understanding of mathematical concepts and processes as well as solve problems through rational analysis and communication. This paper also advocates for developing theories from studies such as the one discussed in this study. This is on the premise that oral communication is one of the most effective methods of improving classroom instruction in all subjects. The paper focuses on the teaching of mathematics in situations that regard the grasping of 
concepts as essential to student learning. It provides a rationale for oral communication across the curriculum. Furthermore, the paper draws from research studies, suggestions for using oral communication in the teaching/learning of mathematics.

\section{Theoretical framework}

In this paper, the writer adopts the theory used in mathematics communication by Vygotsky (1962), who asserts that language is indispensable in learning as it is the logical and analytical thinking tool. This is because thoughts are not merely expressed through the linguistic units such as words but are created through it. Although language may not be essential for the creation of basic concepts, it is needed to build higher concepts. Vygotsky (op.cit) further advocates that learners can reconstruct objective mathematical knowledge as subjective knowledge through social negotiation with knowledgeable others, books, or their peers and students. In this study, as the researcher reviews literature relevant to the study, the question whether teachers' oral communication can be enhanced to build or reconstruct mathematical knowledge would be asked.

\section{Why oral communication is important in the mathematics classroom?}

The importance of oral communication skills in the mathematics classroom can never be over emphasized; undervaluing it will be at one's own peril. Communication is important for students' learning and teaching. The communication skills that students learn now can benefit them in the future. Students need to be able to communicate with their teachers and their peers. Understanding vocabulary can help them to become better communicators. Because of this, this section of the discussion is going to explore the importance of oral communication skills in the mathematics classroom as well as across the curriculum.

Gamble \& Gamble (2010) rightly argue that oral communication refers to words and articulations. Therefore, it is important that an educator is able to understand students' knowledge of a mathematical concept. One way to do this is by asking open-ended questions and teachers can stimulate students' growth of mathematical knowledge through the ways they ask and respond to questions (Piccolo, Harbaugh, Carter, Capraro, \& Capraro, 2008, p. 380). Thus, an articulate teacher can indeed ensure this.

It can be argued that teachers must help students clarify their statements, focus carefully on problem conditions and mathematical explanations, and refine their ideas. Students need to feel comfortable talking about their understanding in order to become better students. As an educator, it is important that one does everything that one can to help students be comfortable in the classroom. The more comfortable they are, the more they may be willing to communicate. Therefore, Sherin $(2000,122)$, rightly argues that teachers are encouraged to provide opportunities for students to discuss their ideas about mathematics and to listen closely to what students say. It is important to listen to students when they 
communicate so that they can be encouraged and helped in their task of solving mathematical problems.

Communication is not just vital for the mathematics classroom, but in all classrooms. Therefore, all educators must be aware of the importance of being able to communicate with students, to have students communicate with one another, and to have students understand what they are communicating about. Kabasakalian $(2007,843)$ correctly contends that "the need for meaningful classroom discourse is now universally accepted among educational researchers and teachers are encouraged to use 'higher order' questions." Thus, oral communication skills are key for any teacher and student alike. Educators have to be willing to push students to become good communicators.

The following quotation is telling to answering the question or proposition on the importance of oral communication skills in the mathematics classroom:

"Oral Communication includes talking, listening, questioning, explaining, defining, discussing, describing, justifying, and defending. When students participate in these actions in an active, focused, and purposeful way, they are furthering their understanding of mathematics." (Ontario Ministry of Education, 2006, p. 66)

From the above, it is evident that indeed oral communication is important as it furthers students' understanding of mathematics.

Further, Baroody, (1993) and Gardner, (1983) also view communication skills and the ability to think and solve problems scientifically as the most valued skills in educational practices globally presently. Hence, teachers need to communicate mathematics effectively while they are engaged in the process of active construction of knowledge as mathematics is a language and science of patterns (Washington State Instructional Materials Review, 2006) and its symbols and vocabulary are a universal means of communication about relationships and patterns. It is a mode of inquiry that relies on logic, observation, simulation and experimentation to challenge and extend our current understanding. Therefore, mathematics teachers need to learn to share ideas and clarify their understanding of mathematics while they form mathematical ideas when they reflect, discuss, modify, and explain the conceptual structure to their peers and pupils. This cycle of analytical and systematic reasoning will eventually reinforce and strengthen the pupils' knowledge and understanding of mathematics, thus causing them to think deeply and this could help in their teaching and learning.

Scholars have strongly argued that teachers' growth evolved interactively through a process of enaction and reflection, when they think and communicate (Huang \& Bao, 2006; Clarke \& Hollingsworth, 2002). The following quotation is more revealing: 
"At the heart of mathematics is the process of setting up relationships and trying to prove these relationships mathematically in order to communicate them to others. Creativity is at the core of what mathematicians do. "(Fosnot \& Dolk, 2001, p. 4)

Therefore, the secret to successful teaching is being able to determine what students are thinking and then using that information as the basis for instruction. Teachers learn what students are thinking through student communication. When students communicate mathematically, either orally or in writing, they make their thinking and understanding clear to others as well as to themselves. In the early grades, students' thinking about mathematics is often difficult to explore, primarily because students' skills in talking and writing are just beginning to develop and because their experience of communicating about mathematics is new. Throughout the primary grades and into the junior years, however, students gain more experience and are given many opportunities to acquire an increasing number of strategies for demonstrating what they understand mathematically and demonstrating the process they used to find a solution. Having students communicate mathematically helps teachers to:

- gauge students' attitudes towards mathematics;

- understand student learning, including misconceptions that students have;

- help students make sense of what they are learning;

- recognize and appreciate another perspective.

When communication is emphasized in the mathematics program, students also have many opportunities to develop and reinforce their literacy skills. In order to investigate mathematical concepts and solve mathematical problems, students need to read and interpret information, express their thoughts orally and in writing, listen to others, and think critically about ideas. Most of the communication strategies described in this article are not unique to mathematics learning - they are instructional techniques that can be used across the curriculum.

In summary, oral communication skills can be argued to be essential, not only in the mathematics classroom, but across the curriculum as it fosters students understanding and learning. Through questioning, explaining, sharing ideas, describing, justifying, and defending; students participate in these actions in an active, focused, and purposeful way. By so doing, they would be furthering their understanding of mathematics.

\section{Review of literature on the enhancement of oral communication skills for teachers of mathematics}

This section of the discussion reviews four articles of research in the teaching and learning of mathematics. These articles have been chosen purposefully as they deal with the enhancement of oral communication skills in the teaching and learning of mathematics. In reviewing these articles, the researcher is particularly concerned 
with that part that is telling and informing when it comes to ways in which the oral communication skills of teachers of mathematics can be improved.

Peterson's (2005) "Student Teaching In Japan: The Lesson," shows that it is clear from the observations he made that the focus of student teaching in schools is on the lesson. In using the term lesson, he argues, it would be valuable to use it in the context of the Japanese word for lesson which is jugyo. In Japanese, jugyo means teaching, instruction and school work as well as lesson. Thus, to say that the lesson is the focus of Japanese student teaching, does not mean just the physical, written out lesson plan, but the whole process of teaching a lesson from preparation to teaching to reflection. In this process, student teachers also gain experience observing lessons where they focus on student thinking, the content of the lesson, the sequencing of ideas and not just the presentation of the lesson. One component of the interactions between the cooperating teacher and student teacher was a continual emphasis on how the students were making sense of the problems and questions presented. Cooperating teachers frequently asked questions like "How will the students answer that question?" or "what was the student's understanding when he made that comment?" These types of questions shaped the direction of each lesson and meeting between cooperating teachers and student teachers.

From the above it is also clear that indeed the interactions (thus oral communication skills) are indeed vital in the development of the teachers as they also go a long way to aid students learning of mathematics.

In an article, "Enhancing Communication Skills in Mathematics Teachers through the Lesson Study Collaboration: A Pilot Study," Ong, Lim and Ghazali (2007) argue that due to technological advances, mathematics teachers must be able to interpret and use mathematics to make sense of information and complex situations. They go further to attest that these teachers must develop and hone their skills through deeper understanding of mathematical concepts and processes, solve problems by reasoning and communication. They intended to improve teachers' communication skills through what they term 'a lesson study process'. Their study found out that indeed teachers' verbal communication skills were improved through group discussions, teachers' participation, discussion, arguments, reactions, compromises or consensus, changes attempted and realized or aborted. They also argued that through this lesson study collaboration, students would become more confident, inquisitive and enthusiastic for the job market. Again, they attest that the teachers involved in the study could then think critically and creatively, solve problems and have the ability to adapt themselves to an everchanging global environment.

This study has shown that Lesson Study collaboration helps primary school mathematics teachers improve their verbal communication skills. They build their confidence in expressing ideas, improve their reflective practices and enhanced their questioning strategies. It was also noticed that when the teachers were excited and wanted to prove a point, they reverted to code-switching especially in their first language, when they wanted to justify why they used 
certain teaching and learning strategies. They also communicated in their first languages to encourage their colleagues who were not confident to use English and this has helped to build collegial ties as a few teachers have many good ideas but were constrained in expressing them initially. After the collaboration process, they managed to share eloquently. The practice of "throwing back" questions to encourage thinking was clearly demonstrated and teachers enjoyed this intellectual discourse tremendously. In their group discussions, teachers' participation and discussions, communication among mathematics teachers has been enhanced. Further explanation on how 'Lesson Study' collaboration enhances mathematics teachers' communication skills is given below.

Research has shown that lesson study can indeed enhance mathematics teachers' communication skills. The two articles so far reviewed attest to that effect, that lesson study does enhance mathematics teachers' oral communication skills in particular and communication skills in general. Thus, the researcher felt it could be pertinent to elaborate how lesson study collaboration enhances mathematics teachers' communication skills.

To begin with, Yoshida (1999) first coined the word "lesson study", which is derived from the Japanese word "jugyokenkyuu", i.e., "jugyo" means lesson and "kenkyuu" means study or research. Lesson study provided a platform of systematic inquiry into teaching practice. It became a quality cycle for establishing long-term goals, where each piece of work is measured against the goals, thereafter; changes are made accordingly (Fernandez \& Chokshi, 2002; Richardson, 2001; Yoshida, 1999). Lesson study is not merely a professional development activity (Watanabe, 2002) but rather became a culture whereby teachers communicated with one another, resulting in deep reflection on subject, students and instructional approaches. Lesson study enhanced and generated new knowledge through practical inquiry (Franke, Carpenter, Levi, \& Fennema, 2001; Stigler \& Hiebert, 1999).

In addition, lesson study helps teachers build conceptual knowledge, especially when they explored different ways to approach the subject or a particular topic. Teachers started by examining the contents deeply to find connectedness across grades by searching between lines in text-books so that they can integrate the details and content for the lesson (Clarke, 2006; Takahashi, 2006). This collaboration provided the teacher the time and structure to focus on her students and develop appropriate strategies based on their needs, besides analysing and improving teaching and learning of even the most challenging unit (Ball \& Cohen, 1999).

Furthermore, Lesson Study enabled teachers to collaborate and internalize learning to teach (Watanabe, 2002; Peterson, 2005). His peers and knowledgeable others could contribute to his growth (Ross \& Bruce, 2007). Through this process, teachers became more observant and focus on meaningful problems, which are linked to real-life, which students can relate to. Therefore, from the above it is evident that research has shown that one way of improving mathematics teachers' communication skills is through the lesson study mode. 
Another article reviewed, "Look Who's Talking- Incorporating oral presentations into mathematics" by Anne B D'Arcy-Warmington $(2008,2)$ argues that "... simply speaking, the problem is we are not speaking (writer's italics)." The solution is a true collaboration by both student and mathematics educator which may require a radical change in the administration of tutorials. This change is required for two-way conversation to take place. Students need to be aware that the first step to mathematical comprehension is talking about mathematical concepts rather than a written solution. Public speaking is enemy number one in mathematics sessions as students would gladly attempt endless written questions rather than have to find words to explain their mathematical ideas. To overcome fear and shyness, students must be introduced slowly to the idea of discussing concepts instead of solutions. Emotions play a major part in learning, especially in mathematics, so a top priority is to create a friendly social atmosphere from day one where students employ their interpersonal and linguistic intelligences. Both tutor and student need to adapt to this social aspect not as an 'add-on' component but as an integral enhancement to learning.

D'Arcy-Warmington also goes further to argue that it is important to consider the merits of oral presentations in mathematics service units as students' educational needs are diverse. Reaching parts of the brain that usual educational methods do not reach may be the answer to those poor students who do not have a 'mathematical brain'. The theory of multiple intelligences and brain-based learning may be the tool that will aid these students to be more confident about their mathematical ability. A broad knowledge and appreciation of mathematics is required. So examination questions that are easily solved by rote learning and algorithms will not have any educational advantage to these students in their chosen field. Oral presentations provide all students with a chance to display their knowledge in fun and creative ways. The interest aroused when researching the topic may give rise to a new curiosity about mathematics. With the declining numbers of students wishing to study mathematics perhaps an injection of creativity in service units may spark an interest in mathematics in students.

In addition, another article: "Integrating Oral Presentation into Mathematics Teaching and Learning: An Exploratory Study with Singapore Secondary Students" by Fan Lianghuo Yeo Shu Mei was also reviewed. In this paper, the writers introduced an exploratory study on the integration of oral presentation tasks into mathematics teaching and learning in five classes taught by different teachers in two Singapore secondary schools over a substantial period of time. From the results obtained from this study, it appears that although both teachers and students encountered initial difficulties and challenges, with necessary experiences and skills over time they can overcome them and become quite effective in using oral presentation in their teaching and learning. Therefore, oral presentation can be reasonably implemented in mathematics classrooms. The results also showed that both teachers and students overall developed positive views about the benefits and usefulness of using oral presentation tasks into their daily mathematics teaching and learning. 
These positive views, it can be argued are related to the nature and pedagogical values of oral presentation activities. It was also observed in the study that, to effectively integrate oral presentation into the process of mathematics teaching and learning, both teachers and students should take various roles and responsibilities during the engagement. In particular, teachers' beliefs, behaviour, reaction and verbal responses to students' speech attributed to the effectiveness of using oral presentation in mathematics teaching. Teachers need to recognize that opportunity for students to be involved in active and meaningful verbal communication is an essential process for their learning and knowledge acquisition. They also need to give students necessary guidance (including making clear the expectations) especially at the initial stage, and more importantly, create encouraging classroom environment for students to engage themselves in such communication.

Finally, given the fact that the use of oral presentation tasks is relatively new to many teachers and students, and in fact, to the general school system about teaching and assessment in Singapore classroom settings, it seems clear that timely evaluation, fine-tuning work and systemic reform in school assessment are important for the effective integration of oral presentation in teaching and learning in the long run. Nevertheless, from this study it can be argued that given necessary help and guidance for teachers and students, it is not only meaningful but feasible to integrate oral presentation tasks into mathematics teaching and learning.

\section{Discussion}

The studies analysed above have been consistent in demonstrating that many of the constructs hypothesized in communication skills studies can be implemented. The lesson study has been affirmed by the first two researchers analysed to contribute immensely to the improvement of teaching and learning of mathematics. Peterson (2005) in an earlier study contends that the lesson study collaboration used as part of teacher training in Japan has commendable benefits in the enhancement of mathematics teachers' oral communication skills. These benefits have been clearly outlined in a later study by Ong, Lim and Ghazali (2008) when they argue that the lesson study collaboration improved the teachers' verbal communication skills through group discussions, teachers' participation, discussion, arguments, reactions, compromises or consensus, changes attempted and realized or aborted. They also argued that through this lesson study collaboration, students have become more confident, inquisitive and enthusiastic for the job market. Again, they attest that the teachers involved in the study could now think critically and creatively, enhanced their questioning strategy, solve problems and have the ability to adapt themselves to an ever-changing global environment. Furthermore, after the collaboration process, it is argued that teachers reduced code-switching and managed to share eloquently.

The second set of similar research in the enhancement of teachers' oral communication skills through oral presentations also made interesting and informative reading. Firstly, Lianghou and Shu Mei (2007) in their argument for 
the integration of oral presentation tasks in the teaching and learning of mathematics to secondary school pupils, propound that this integration has proven vital as oral presentation tasks help students understand and learn mathematics. The teachers interviewed generally felt that as long as an oral task was appropriately designed to measure students' specific learning outcomes, then the oral task could be used as a measurement about students' learning. These teachers also felt that some of the conventional tasks could be replaced by oral presentation tasks. For instance, one teacher pointed out that "[oral presentation tasks are] a reliable source to find out from students whether they had internalized what they had learnt rather than just solve questions" (Lianghou \& Shu Mei, 2007).

Secondly, D'Arcy-Warmington (2008) advocates for the enhancement of oral communication skills through a radical change in the administration of tutorials to encourage a true two-way conversation, that is, between the tutor and among the students. In addition, the scholar argues that students comprehend mathematics through talking about mathematical concepts rather than a written solution thus oral communication skills become handy for the teacher and eventually the student. This is so as the teacher then encourages the students to discuss the concepts instead of the solutions. These discussions have been seen to create a friendly social atmosphere to counter emotional barriers that might hinder learning as students employ their interpersonal and linguistic intelligences to aide them in their learning. Further, D'Arcy-Warmington (2008) also argues that oral presentations can help students understand mathematics better as they provide students with a chance to display their knowledge in fun and creative ways.

Therefore, it is evident from the above discussion that oral communication skills can be enhanced in the mathematics classroom for the improvement of the teaching and learning of the subject.

\section{Conclusion}

The study has been a highlight of the lessons that could be drawn from research in as far as the enhancement of mathematics teachers' oral communication skills. Four articles have been reviewed. Two of these mainly emphasized that indeed mathematics teachers' oral communication skills can be enhanced through the lesson study collaboration process both in the teacher-training programmes as well as a way of upgrading and developing practising teachers through refresher courses. The other two studies have argued for the integration of oral presentation tasks in the teaching and learning of mathematics so as to enhance both the student and the teacher's oral communication skills as they entail a creative and fun filled way of learning. Be that as it may, these findings are yet to be documented in as far as the Zimbabwean context is concerned. Therefore, the researcher is calling for scholarly inquiry into filling of this lacuna. 


\section{References}

Ball, D., \& Cohen, D. (1999). Developing practice, developing practitioners: Towards a practicebased theory of professional education. San Francisco: Jossey-Bass.

Baroody, A. J. (1993a). Fostering the mathematical learning of young children. In B. Spodek (Ed.), Handbook of research on the education of young children. New York: Macmillan.

Baroody, A. J. (1993b). Problem-solving, reasoning, and communicating, K-8. In Helping Children Think Mathematically. Toronto, ON: Maxwell Macmillan Canada.

Clarke, D. (2006). Professional Development: An Australian case: The power of one-to-one assessment interviews. Paper presented at the APEC International Symposium on Innovation and Good Practices for teaching and learning mathematics through Lesson Study. Khon Kaen Thailand

Clarke, D., \& Hollingsworth, H. (2002). Elaborating a model of teacher professional growth. Teaching and Teacher Education, 18(8), 946-967.

D'Arcy-Warmington, A. B. (2008) “Look Who's Talking- Incorporating oral presentations into mathematics" retrieved from tsg.icme11.org/document/get/549 on 5/8/2013.

Fernandez, C., \& Chokshi, S. (2002). A practical guide to translating lesson study for a U.S. setting. Phi Delta Kappan, 84(2).

Fosnot, C., \& Dolk, M. (2002). Young mathematicians at work: Constructing fractions, decimals, and percents. Portsmouth, NH: Heinemann.

Franke, M. L., Carpenter, T. P., Levi, L., \& Fennema, E. (2001). Capturing teachers"e generative change. A follow-up study of professional development in mathematics. American Educational Research Journal, 38, 653-689.

Gardner, H. (1983). Frames of mind: The theory of multiple Intelligences New York: Basic Books. 8

Huang, R., \& Bao, J. (2006). Towards a model for teacher professional development in China: Introducing Keli. Journal of Mathematics Teacher Education, 2006(9), 279-298.

Ontario Ministry of Education. (2006). Communication in the Mathematics Classroom [Electronic Version] retrieved from www.edu.gov.on.caleng/.../CBS_Communication_Mathematics.pdf on 3/7/2013.

Ong, E.G., Lim, C. S. and Ghazali, M. (2007). "Enhancing Communication Skills in Mathematics Teachers through the Lesson Study Collaboration: A Pilot Study," retrieved from www.recsam.edu.my/cosmed/cosmed07/.../Mathematics\%5CM015F.pdf on 2/7/2013.

Peterson, B. E. (2005). Student Teaching in Japan: The Lesson. Journal of Mathematics Teacher Education, 61-74.

Richardson, J. (2001). National Staff Development Council.

Ross, J. A., \& Bruce, C. D. (2007). Teacher self-assessment: A mechanism for facilitating professional growth. Teaching and Teacher Education, 23(2), 146-159. 
Stigler, J. W., \& Hiebert, J. (1999). The teaching gap: Best ideas from the world's teachers for improving education in the classroom: Free Press.

Takahashi, A. (2006, 13-17 June, 2006). Implementing Lesson Study in North American Schools and School. Paper presented at the APEC International Symposium on Innovation and Good Practice for Teaching and Learning Mathematics through Lesson Study, Khon Kaen Thailand.

Vygotsky, L. S. (1962). Thought and language. Cambridge Massachusetts: The M.I.T.

Washington State Instructional Materials Review. (2006). The K-12 Mathematics and Reading Core/Comprehensive Instructional Materials Report [Electronic Version]. Retrieved 31/1/2013 from http://www.k12.wa.us/CurriculumInstructMathematics/default.aspx.

Watanabe, T. (2002). Learning from Japanese Lesson Study. Educational Leadership, 59(6).

Yoshida, M. (1999). Lesson Study (Jugyokenkyu) in elementary school mathematics in Japan: A case study. Paper presented at the 1999 Annual Meeting of American Educational Research Association 